\title{
CARACTERIZAÇÃO DO AMBIENTE DE NEGÓCIOS PARA PRODUÇÃO DE MADEIRA SERRADA NO BRASIL E NO CANADÁ
}

\author{
Alexandre Nascimento de Almeida ${ }^{1}$, João Carlos Garzel Leodoro da Silva ${ }^{2}$, Humberto Angelo ${ }^{3}$ \\ ${ }^{1}$ Eng. Florestal, Dr., Curso de Gestão Ambiental e de Agronegócio, UnB/FUP, Planaltina, DF, Brasil - alexalmeida@unb.br \\ ${ }^{2}$ Eng. Florestal, Dr., Depto. de Economia Rural e Extensão, UFPR, Curitiba, PR, Brasil - garzel@ufpr.br \\ ${ }^{3}$ Eng. Florestal, Dr., Depto. de Engenharia Florestal, Brasília, DF, Brasil - humb@unb.br \\ Recebido para publicação: 12/04/2011 - Aceito para publicação: 16/06/2011
}

\begin{abstract}
Resumo
O objetivo deste estudo é comparar algumas características do ambiente de negócios para produção de madeira serrada do Brasil e do Canadá, bem como analisar a percepção dos empresários desses países em relação à competitividade global do segmento. A importância deste estudo está na comparação de informações referentes ao segmento de madeira serrada do Brasil e Canadá, subsidiando a formulação de políticas voltadas para o aumento da competitividade brasileira. O material contemplou dados primários e secundários referentes às características explicativas da competitividade, que foram analisados por meio de estatística descritiva. Os resultados indicaram que as contribuições da indústria da madeira no PIB são semelhantes para o Brasil e Canadá e que empresas canadenses possuem maior porte, especialização e orientação ao mercado internacional, sugerindo que a principal diferença entre Brasil e Canadá deve-se muito mais ao grau de desenvolvimento do que ao tamanho dos seus segmentos de madeira serrada.
\end{abstract}

Palavras-chave: Mercado florestal; pesquisa de opinião; competitividade; Canadá; negócios florestais.

\begin{abstract}
Business environment description for softwood lumbers production in Brazil and Canada. The objective of this study is to compare some characteristics of the business environment for sawnwood production from Brazil and Canada as well as to analyze the perceptions of entrepreneurs in those countries in relation to the overall competitiveness of the segment. The importance of this study is the comparison of information regarding the segment of softwood lumber from Brazil and Canada, supporting the formulation of policies to increase Brazil's competitiveness. The material included primary and secondary data regarding the characteristics that explain the competition and were analyzed using descriptive statistics. The results indicated that the contributions of the timber industry in GDP are similar to Brazil and Canada and that Canadian companies are larger, more specialized and oriented to international markets, suggesting that the main difference between Brazil and Canada must be more to degree of development than the size of its segments of lumber.

Keywords: Forest market; survey opinion; competitiveness; Canada; forestry business.
\end{abstract}

\section{INTRODUÇÃO}

Nas últimas décadas, observou-se um aumento acentuado da competitividade entre as empresas, forçando-as a um contínuo aprimoramento de seus produtos, processos e serviços. Junto com essa demanda, surgiram várias técnicas visando o aumento da competitividade das empresas, e uma delas é o benchmarking.

$\mathrm{O}$ processo de benchmarking envolve uma análise comparativa entre agentes econômicos, podendo esta ser entre empresas, segmentos ou países, o que possibilita identificar, entre outros fatores, quem tem um processo ou produto melhor. Depois, é necessário entender a razão, para que a base de comparação considerada tenha um processo ou produto melhor. A partir disso, é feita uma adaptação do que a empresa-referência precisa fazer para promover a melhora do seu desempenho. 
Para o segmento de madeira serrada, um padrão mundial a ser perseguido e bom parâmetro de comparação é o Canadá. Segundo a Organização das Nações Unidas para Agricultura e Alimentação (FAO, 2010), nas últimas décadas, o Canadá tem sido o maior exportador mundial de madeira serrada, refletindo a sua alta competitividade nesse segmento. Enquanto o Canadá respondeu por $21 \%$ de todo o comércio mundial de madeira serrada de coníferas em 2009, a participação brasileira não chegou a $1 \%$.

A busca do aprimoramento das práticas pela comparação com os melhores padrões mundiais não implica apenas conhecer, aprender e copiar os melhores exemplos, mas envolve o conhecimento das vantagens competitivas de ambos os países, base preponderante para o estabelecimento de uma estratégia eficiente.

O objetivo deste trabalho foi comparar algumas características do ambiente de negócios para produção de madeira serrada do Brasil e do Canadá e analisar a percepção dos empresários do Brasil e do Canadá em relação à competitividade do segmento de madeira serrada.

\title{
MATERIAL E MÉTODOS
}

\begin{abstract}
Amostragem
O universo da abordagem desta pesquisa é constituído pelas empresas que comercializam madeira serrada mole (softwood lumber ou, em geral, provenientes do gênero das coníferas) entre o mix de seus produtos. Para o Brasil, a pesquisa foi delimitada apenas para empresas que produzem madeira serrada a partir de fonte plantada, predominando as serrarias presentes nas regiões Sul e Sudeste do País. Para o Canadá, a amostragem representou todo o seu território.

A obtenção dos dados foi por meio do envio aleatório de questionários para as empresas de madeira serrada, pelo correio, fax ou e-mail, precedido de contato telefônico para solicitação de apoio à pesquisa. Também foram obtidos alguns questionários respondidos via aplicação direta em feiras, seminários e congressos do segmento e em visitas às empresas. A obtenção dos contatos das empresas foi a partir das diversas associações, federações e sindicatos, bem como pela lista telefônica.

A coleta dos dados ocorreu no período de janeiro a julho de 2008, possibilitando a obtenção de 66 questionários respondidos para o Brasil e 40 para o Canadá, correspondendo a, aproximadamente, 3 e $10 \%$ da população total de serrarias brasileiras e canadenses, respectivamente (SPELTER; ALDERMAN, 2005; INSTITUTO BRASILEIRO DE GEOGRAFIA E ESTATÍSTICA/IBGE, 2010), o que evidencia que o percentual amostral de $3 \%$ para o Brasil refere-se à população de empresas que serram madeira plantada, principalmente coníferas.

Conforme o IBGE (2010), em 2008 o Brasil tinha 4.122 serrarias, e apenas as regiões Sul e Sudeste contabilizavam 2.311 empresas, refletindo aproximadamente o número de empresas que trabalham com madeira proveniente de silvicultura no País. Já no Canadá, conforme Spelter e Alderman (2005), o número total foi de 404 serrarias em 2004.
\end{abstract}

\section{Dimensionamento da amostra}

A determinação do tamanho da amostra em trabalhos de pesquisa experimental é de significativa importância, considerando-se a correção da determinação da validade estatística no experimento (WEYNE, 2004). Porém, coletar uma amostra que possibilite um erro estatístico baixo pode ser inviável economicamente, restando ao pesquisador a tarefa de apenas avaliar a limitação da amostra conseguida e decidir pela continuidade ou não da pesquisa.

Devido aos dados coletados estarem em escala nominal, a determinação do tamanho da amostra teve como base a estimativa da proporção populacional para população infinita expressa pela equação 1 (MARTINS, 2006).

$$
n=\frac{1,96^{2} \times 0,25}{E^{2}}
$$

em que: $\mathrm{n}=$ número de indivíduos na amostra;

$E=$ margem de erro.

A equação 1 , para determinação do tamanho da amostra, assume a ideia de que a população de onde a amostra é retirada é tão grande que poderíamos considerá-la infinita. Entretanto, a maior parte das populações não é tão grande quando comparadas com as amostras. Caso a amostra tenha um tamanho (n) 
maior ou igual a $5 \%$ do tamanho da população $(\mathrm{N})$, considera-se que a população seja finita. Nesses casos, aplica-se um fator de correção na equação 1 , e a nova fórmula para a determinação do tamanho da amostra passa a ser conforme a equação 2 (LEVINE et al., 2000).

$$
n=\frac{N \times 0,25 \times 1,96^{2}}{0,25 \times Z_{\alpha / 2}^{2}+(N-1) \times E^{2}}
$$

Em virtude de a amostra do Brasil corresponder a aproximadamente 3\% da população (66 casos para uma população de aproximadamente 2.311 empresas) e a amostra do Canadá ser superior à representatividade de 5\% requerida pela equação 2 (40 casos para uma população de 404 empresas), a equação 1 foi aplicada para o Brasil e a equação 2 para o Canadá na avaliação da margem de erro de suas amostras.

\section{Caracterização do segmento de madeira serrada do Brasil e Canadá}

A caracterização do Brasil e do Canadá contou com informações macroeconômicas, seguidas de informações gerais da indústria do processamento mecânico, e, por fim, foram obtidas informações específicas dos segmentos de madeira serrada de ambos os países, inclusive no que diz respeito à percepção geral sobre a competitividade global. Estas últimas informações foram referentes ao sentido da palavra competitividade, tendo sido perguntado aos empresários quais países são entendidos como os mais competitivos e as razões para as suas escolhas.

Os instrumentais analíticos utilizados foram: análises gráficas com dados de corte e séries históricas, cálculos de porcentagem com dados primários e secundários e ordenação dos dados conforme suas magnitudes, ou seja, optou-se pela estatística descritiva, prezando pela simplicidade e permitindo uma leitura rápida das características apresentadas.

As informações macroeconômicas apresentadas corresponderam ao indicador normalmente utilizado para se analisar o tamanho de uma economia, o Produto Interno Bruto (PIB), e aos indicadores aplicados para referenciar o grau de desenvolvimento de uma nação: o PIB per capita e o Índice de Desenvolvimento Humano (IDH).

As informações gerais da indústria do processamento mecânico foram embasadas nas informações sobre a sua contribuição para as economias do Brasil e do Canadá. Também foi apresentada a posição global do Brasil e do Canadá na produção e exportação da maioria dos produtos de madeira sólida para 2009.

Como informações específicas do segmento de madeira serrada do Brasil e do Canadá, apresentaram-se dados primários referentes: a) às principais espécies utilizadas; b) ao porte das empresas; c) à importância da madeira serrada na receita das empresas; e d) ao portfólio de produtos comercializados. Além dessas, analisaram-se outras informações específicas do segmento de madeira serrada de coníferas, provenientes de dados secundários de produção, consumo e exportação.

\section{RESULTADOS E DISCUSSÕES}

\section{Dimensionamento da amostra}

As amostras coletadas de 66 e 40 casos, para o Brasil e o Canadá, respectivamente, representaram a população com uma margem de erro de $12 \%$ para o Brasil e $15 \%$ para o Canadá, o que é perfeitamente aceitável para amostras dessa natureza.

No que diz respeito à validação do tamanho da amostra acima do nível normalmente estipulado de 5\%, destacam-se as considerações de Almeida (2006). Conforme o autor, dependendo do caráter e objetivo do experimento, o nível de significância pode ser mais ou menos exigente que $5 \%$. O fato é que, em trabalhos econômicos, além de os dados usados serem observados na vida real e não derivados de experimentos-controles, o comportamento econômico é, até certo ponto, irregular, sendo influenciado por eventos impossíveis de predizer.

Dessa forma, a tolerância em experimentos econômicos deve ser maior do que aquela relacionada, por exemplo, a experimentos da área da medicina, os quais são ligados diretamente com a vida das pessoas, bem como quando comparado com experimentos em que é permitido um maior controle das variáveis, como os ligados à área de inventários florestais. 


\section{Caracterização do segmento de madeira serrada do Brasil e do Canadá}

Atualmente, a economia brasileira é maior que a canadense. Em 2008, o PIB brasileiro foi de US\$ 1,6 trilhão, ocupando a oitava posição mundial e ficando três posições à frente do PIB canadense, que foi de US\$ 1,4 trilhão (NAÇÕES UNIDAS/UN, 2010). Porém, o PIB per capita do Brasil nesse mesmo ano ocupou a $94^{\mathrm{a}}$ posição mundial, com um valor próximo de US\$10 mil por habitante, ficando 70 posições atrás do PIB per capita de US\$ 35,6 mil do Canadá (GAPMINDER, 2010).

Visto que as medidas de PIB e PIB per capita não são os melhores indicadores do grau de desenvolvimento de uma nação, a medida atualmente mais utilizada para essa avaliação é o IDH, e nesse critério o Brasil também se localiza bem distante do Canadá. Em 2007, o IDH de 0,97 do Canadá foi o quarto maior do mundo, enquanto o Brasil ocupou apenas a $75^{\mathrm{a}}$ posição global, com um IDH de 0,81 , atrás até dos vizinhos sul-americanos: Chile, Argentina, Uruguai e Venezuela (PROGRAMA DAS NAÇÕES UNIDAS PARA O DESENVOLVIMENTO/PNUD, 2010).

O IDH denota a característica de país desenvolvido do Canadá. Em geral, os países desenvolvidos apresentam melhores condições em diversas variáveis relacionadas a maiores níveis de educação, menor burocracia e infraestrutura desenvolvida, entre outros aspectos presentes nesses países e que são importantes para a competitividade de todos os setores da economia.

Do mesmo modo que para a economia em geral, aparentemente a distância entre o setor florestal do Brasil e o do Canadá, principalmente em relação à indústria do processamento mecânico, está mais relacionada ao grau de desenvolvimento do que ao tamanho.

A partir de 2006, a indústria de base florestal no Brasil passou a gerar um montante absoluto de riqueza superior ao da indústria canadense. Segundo a Associação Brasileira da Indústria de Madeira Processada Mecanicamente/ABIMCI (2008), a indústria de base florestal no Brasil gerou US\$ 44,6 bilhões em 2007, respondendo por 3,4\% do PIB nacional. No mesmo período, conforme Recursos Naturais do Canadá/NRC (2010), a indústria de base florestal daquele país contribuiu com cerca de US\$ 31,7 bilhões, valor 29\% inferior ao do brasileiro, representando 2,2\% do PIB canadense.

Já as contribuições ao PIB do segmento do processamento mecânico (produtos de madeira sólida) do Brasil e do Canadá foram praticamente iguais em 2007 (ABIMCI, 2008; NRC, 2010), porém o número de empregos gerados diretamente em seus respectivos países foi bastante diferente. Enquanto a contribuição do processamento mecânico brasileiro, de, aproximadamente, US\$ 13 bilhões em 2007, necessitou de 225 mil pessoas empregadas, no Canadá foram apenas 147 mil pessoas (IBGE, 2010; NRC, 2010).

A necessidade de $35 \%$ menos trabalhadores para alcançar quase a mesma contribuição ao PIB configura o caráter de capital intensivo da indústria canadense, o que evidencia maior desenvolvimento tecnológico, quando comparado ao Brasil, variável essa altamente importante para a competitividade canadense.

A importância da tecnologia para competitividade é tamanha que uma corrente de pensamento iniciada por Schumpeter coloca a inovação como elemento central da competitividade, minimizando a importância de todas as outras variáveis. Nessa linha destacam-se os trabalhos de Freeman (1994), Sem e Egelhoff (2000), Guan et al. (2006) e Possas (1996).

Segundo Freeman (1994), no longo prazo, é a capacidade de inovação tecnológica que gera uma importante vantagem competitiva. Já Sem e Egelhoff (2000) apontaram que a capacidade de introduzir novos produtos e adotar novos processos em tempo mais curto é uma vantagem competitiva fundamental. Guan et al. (2006) encontraram evidências empíricas que sugeriram a existência de uma estreita relação interna entre inovação tecnológica e competitividade, enquanto Possas (1996) entende inovação e tecnologia como aspectos-chave para a competitividade e destaca a importância do Estado para a indução da capacitação tecnológica e produtiva, provendo os meios públicos necessários (crédito, financiamento, subsídios e incentivos fiscais) e estimulando, ou mesmo favorecendo, a formação de alianças e cooperação, inclusive privada, quando possível e relevante.

Entre os segmentos componentes da indústria do processamento mecânico, o produto de maior destaque, tanto para o Brasil quanto para o Canadá, em 2009, foi a madeira serrada. Para o Brasil, o grande destaque foi a madeira serrada de folhosas provenientes da Amazônia, e para o Canadá, a madeira de coníferas (Tabela 1). 
Tabela 1. Posicionamento global do Brasil e do Canadá na produção e exportação de produtos provenientes da indústria do processamento mecânico da madeira em 2009.

Table 1. Global positioning of Brazil and Canada in the production and export of products from wood mechanical processing industry in 2009.

\begin{tabular}{|c|c|c|c|c|c|c|}
\hline \multirow{3}{*}{ Produtos de base florestal } & \multicolumn{3}{|c|}{ Produção } & \multicolumn{3}{|c|}{ Valor das exportações } \\
\hline & \multicolumn{2}{|c|}{ Posição mundial } & \multirow{2}{*}{$\begin{array}{c}\text { Maior } \\
\text { produtor }\end{array}$} & \multicolumn{2}{|c|}{ Posição mundial } & \multirow{2}{*}{ Maior valor } \\
\hline & Brasil & Canadá & & Brasil & Canadá & \\
\hline Madeira serrada (coníferas) & $9^{\circ}$ & $2^{\circ}$ & EUA & $15^{\circ}$ & $1^{\circ}$ & Canadá \\
\hline Madeira serrada (folhosas) & $3^{\circ}$ & $21^{\circ}$ & EUA & $3^{\circ}$ & $12^{\circ}$ & EUA \\
\hline Laminado & $4^{\circ}$ & $6^{\circ}$ & China & $16^{\circ}$ & $4^{\circ}$ & EUA \\
\hline Compensado & $5^{\circ}$ & $9^{\circ}$ & China & $4^{\circ}$ & $11^{\circ}$ & China \\
\hline Aglomerado & $8^{\circ}$ & $4^{\circ}$ & EUA & $31^{\circ}$ & $3^{\circ}$ & Alemanha \\
\hline Chapa dura & $6^{\circ}$ & $22^{\circ}$ & Alemanha & $7^{\circ}$ & $5^{\circ}$ & Alemanha \\
\hline Chapa isolante & $16^{\circ}$ & $4^{\circ}$ & EUA & $16^{\circ}$ & $10^{\circ}$ & Chile \\
\hline MDF & $5^{\circ}$ & $12^{\circ}$ & China & $37^{\circ}$ & $12^{\circ}$ & China \\
\hline
\end{tabular}

Fonte: FAO (2010).

O Canadá é o segundo maior produtor de madeira serrada de coníferas do mundo. Mesmo após sua produção ter caído pela metade entre 2004 e 2009, os 33 milhões de metros cúbicos de madeira serrada de coníferas produzidos em 2009 ficaram atrás apenas dos 62 milhões de metros cúbicos produzidos pelos Estados Unidos no mesmo ano (FAO, 2010).

O Brasil, por sua vez, vem gradativamente ampliando sua produção de madeira serrada e, com uma produção de 25 milhões de metros cúbicos em 2009, já responde pela quarta produção mundial, ficando atrás apenas dos Estados Unidos, do Canadá e da China (FAO, 2010).

Diferentemente do Brasil, a produção de madeira serrada canadense concentra-se fundamentalmente em espécies pertencentes à ordem das coníferas. Enquanto $98 \%$ da produção de madeira serrada do Canadá, em 2009, foi proveniente de coníferas, no Brasil foi de 38\% (Figura 1).
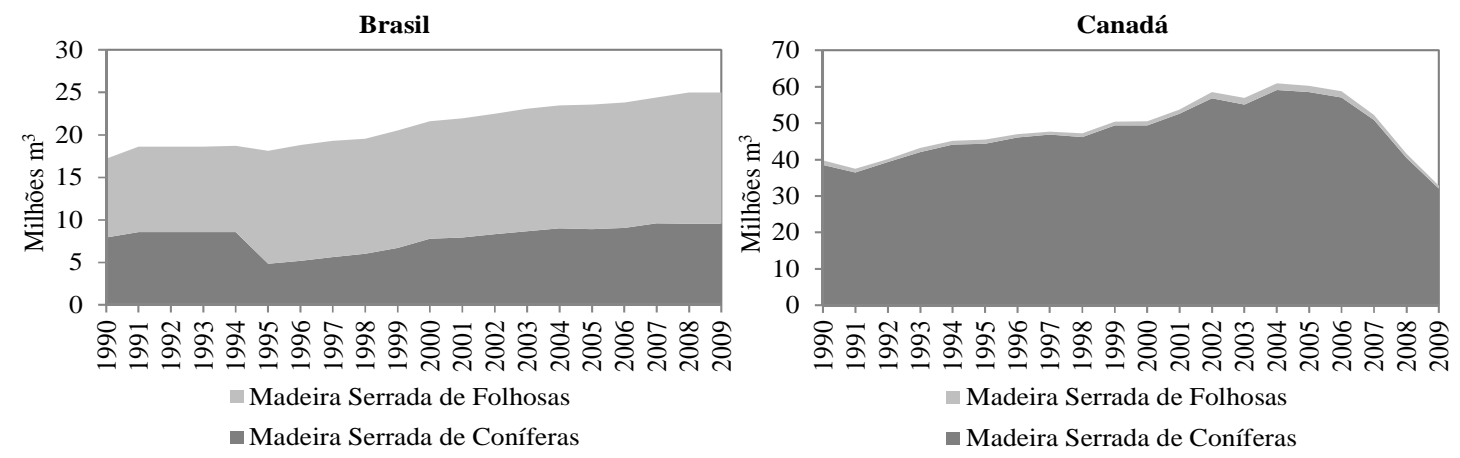

Fonte: FAO (2010).

Figura 1. Evolução da produção de madeira serrada de coníferas e folhosas para o Brasil e o Canadá entre o período de 1990 e 2009.

Figure 1. Production of softwood and hardwood lumber for Brazil and Canada over the period between 1990 and 2009.

A atual estrutura da produção de madeira do Canadá é completamente diferente da brasileira, principalmente em relação à colheita de coníferas. No Brasil, a produção de coníferas concentra-se fundamentalmente no plantio de duas espécies exóticas, o Pinus taeda e o Pinus elliottii, enquanto no Canadá predomina a extração de florestas naturais, concentrando-se em cinco espécies do gênero Picea, conhecidas popularmente por spruce. No Canadá também ocorrem plantios de espécies nativas e introduções de espécies exóticas, porém em uma escala irrelevante, se comparada ao Brasil.

No que tange à extração de florestas folhosas, as estruturas de produção de madeira serrada do Brasil e do Canadá assemelham-se, uma vez que a maioria da madeira explorada de folhosas, em ambos os países, é proveniente de florestas naturais. Entretanto, no Brasil é crescente a produção de madeira 
serrada de folhosas provenientes de plantios dos gêneros Eucalyptus, principalmente o Eucalyptus grandis, e Tectona (Tectona grandis).

Uma diferença clara entre os segmentos de madeira serrada de coníferas do Brasil e do Canadá refere-se aos seus diferentes graus de orientação ao mercado externo. Enquanto esse segmento no Canadá direcionou cerca de $70 \%$ de sua produção ao mercado externo, entre 1990 e 2009, buscando operar em condições de concorrer com os grandes produtores dos países mais desenvolvidos, no Brasil as exportações representaram apenas $12 \%$ da produção (Figura 2).

Alguns trabalhos que relacionam a orientação ao mercado externo com o desenvolvimento de vantagens competitivas são: Dichtl et al. (1993), Diamontopoulus e Inglis (1988) e Axinn (1988). Dichtl et al. (1993), por exemplo, apontaram que os administradores orientados ao mercado externo, além de serem menos avessos aos riscos e menos resistentes a mudanças, possuem menor distanciamento psíquico dos mercados estrangeiros e dos países, alto nível educacional, alto domínio de línguas estrangeiras e maior experiência com outros países, entre outras vantagens competitivas.
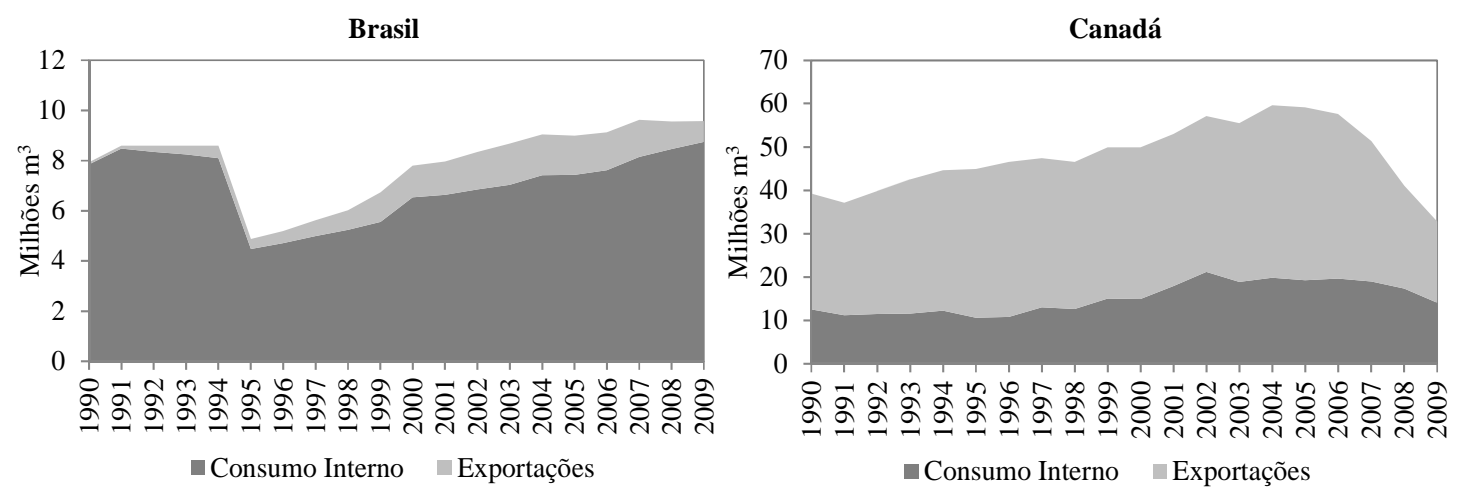

Fonte: FAO (2010)

Figura 2. Evolução do consumo e exportações de madeira serrada de coníferas do Brasil e do Canadá entre o período de 1990 e 2009.

Figure 2. Developments in consumption and exports of softwood lumber to Brazil and Canada over the period between 1990 and 2009.

Uma vantagem competitiva do segmento de madeira serrada do Canadá, em relação à realidade brasileira, deve-se ao maior porte de suas empresas. Dentre as empresas pesquisadas, constatou-se que mais da metade das serrarias do Canadá possui receita anual superior a US\$ 50 milhões, enquanto no Brasil apenas 5\% das empresas alcançaram esse montante em 2007, predominando empresas com faturamento anual inferior a US\$10 milhões (Figura 3).
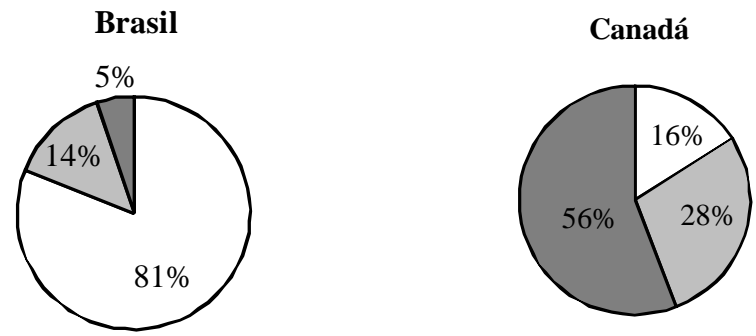

\section{$\square$ Até US\$ 10 milhões $\square$ Entre US\$ 10 e 50 milhões $\square$ Acima de US\$ 50 milhões}

Figura 3. Receita anual das empresas de madeira serrada do Brasil e do Canadá.

Figure 3. Annual income from lumber companies in Brazil and Canada.

O maior porte das empresas no Canadá pode ser confirmado por dados secundários. Segundo o IBGE (2010) e a FAO (2010), em 2008 o Brasil possuía 4.122 serrarias, que produziram cerca de 
25 milhões de metros cúbicos, correspondendo a uma produção média de 6 mil metros cúbicos de madeira serrada por empresa no ano. De acordo com Spelter e Alderman (2005), em 2004 o Canadá produziu cerca de 82 milhões de metros cúbicos, distribuídos em 404 serrarias, ou seja, uma média de 202 mil metros cúbicos de madeira serrada por empresa; quase 34 vezes mais do que no Brasil.

Sendo a madeira serrada um produto de baixa diferenciação, o maior porte e consequentes ganhos em escala de produção tornam-se importantes na definição da competitividade empresarial via preço. Conforme Awh (1979), alguns fatores que contribuem para as economias de escala são: preços mais baixos de insumos, menor custo administrativo por unidade de produto, menor custo de comercialização, menor custo de empréstimos e minimização do risco, devido a uma maior distribuição do mesmo.

Além do maior porte das empresas canadenses, os dados coletados evidenciaram maior diversificação da produção nas empresas brasileiras. Enquanto a madeira serrada correspondeu a mais da metade da receita total em 67\% das empresas no Canadá, no Brasil esse valor foi de 56\% (Figura 4), o que indica maior especialização das empresas canadenses. A especialização propicia uma maior homogeneização dos processos, levando a um maior controle e eficiência das atividades.
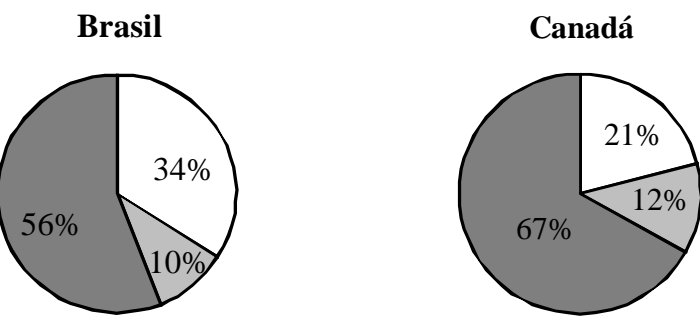

$\square$ Menos de $25 \%$

口Entre 25 e $50 \%$

$\square$ Mais de $50 \%$

Figura 4. Percentual das vendas de madeira serrada em relação ao total das empresas do Brasil e do Canadá.

Figure 4. Percentage of sales of lumber in relation to the total revenue from Brazil and Canada companies.

No Brasil, além de madeira serrada ou beneficiada, alguns produtos indicados como parte do portfólio das empresas foram: esquadrias, componentes para janelas e portas, cabos de vassoura, formas de concreto, lâminas, postes, pallets, resíduos, móveis, cavacos, forro, vigas coladas e painéis, entre outros. Para o Canadá, foram citados o OSB e a madeira em tora para celulose, produtos de capital intensivo e baixa utilização de mão de obra.

Percepção dos empresários brasileiros e canadenses de madeira serrada

A atuação dos empresários para o bom desempenho de qualquer empresa é fundamental, sendo possível encontrar vários exemplos de empresas de sucesso em ambientes estruturais menos competitivos. Segundo Ghoshal e Tanure (2004), pode-se dizer que mesmo em setores com resultados médios ruins, há empresas que, individualmente, se saem muito bem, quase tão bem quanto as de melhor desempenho, nos melhores ambientes de negócio. A percepção dos empresários quanto ao significado da expressão "competitividade global do segmento de madeira serrada", entre os entrevistados no Brasil e no Canadá, foi diferente e denota a visão e objetivos dos mesmos.

Para o empresário brasileiro, ser competitivo depende da habilidade de expansão de mercado, associada a novos produtos. Já para o canadense, o importante é o lucro (Figura 5). O entendimento desses resultados é que o empresário canadense, diferentemente do brasileiro, preocupa-se mais em aumentar a rentabilidade de sua produção, seja pelo aumento de preço ou volume, do que apenas por meio da busca pelo aumento de volume, como sugerido pelo empresário brasileiro.

Os resultados da figura 5 reforçam o entendimento da diversificação em produtos de capital intensivo no Canadá. O empresário canadense definiu claramente seu portfólio e procura lucro com ele, enquanto o empresário brasileiro não.

Para Porter (1993), é esperado que as empresas em países subdesenvolvidos se preocupem principalmente com volume, em virtude das vantagens competitivas desses países tenderem a se situar na 
fartura de recursos naturais e mão de obra barata, porém o autor adverte para essa tendência. Os produtos sustentados pela fartura de matéria-prima e mão de obra, normalmente, são mais sensíveis a preço, deixam o país mais vulnerável à taxa de câmbio e aos custos dos fatores, sofrem mais com políticas protecionistas e acomodam o desenvolvimento tecnológico.
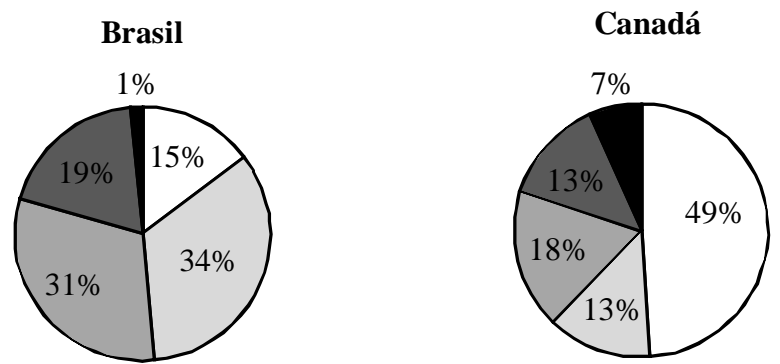

$\square$ A habilidade de gerar maiores lucros do que os competidores

$\square$ A habilidade de aumentar a participação no mercado global

$\square$ A habilidade de inovar em novos produtos

$\square$ A habilidade de estender a cobertura de mercado para novas regiões

- Outros

Figura 5. Frase que transmite o melhor significado da expressão "competitividade global do segmento de madeira serrada" para o Brasil e o Canadá.

Figure 5. Phrase that best conveys the meaning of "global competitiveness in the softwood lumber segment" for Brazil and Canada.

Em duas outras perguntas presentes no questionário, foi pedido para os empresários se posicionarem sobre quais países apresentam o melhor ambiente de negócios para investir no segmento de madeira serrada e, em seguida, apontarem os motivos que levaram à resposta da questão anterior.
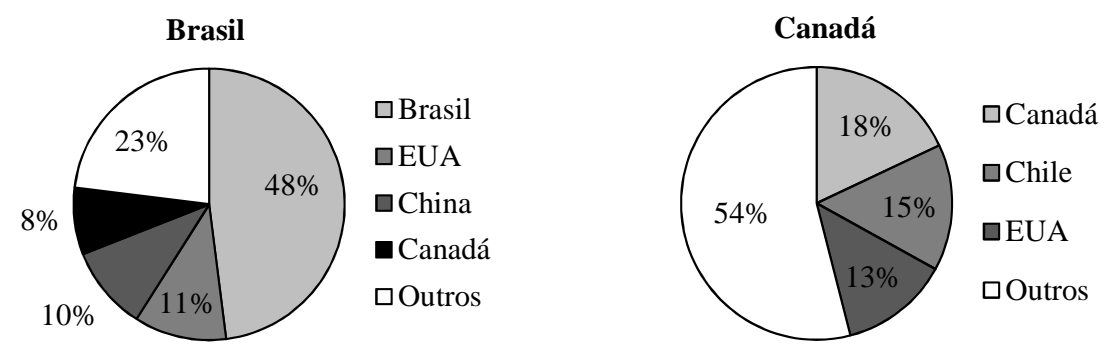

Figura 6. Países que oferecem o melhor ambiente de negócios para investir no segmento de madeira serrada, conforme a opinião dos empresários do Brasil e do Canadá.

Figure 6. Countries that offer the best environment for business to invest in the softwood lumber segment according to the businessmen opinion from Brazil and Canada.

Naturalmente, por falta de informação sobre os ambientes de negócios de outros países, alguns empresários não responderam essas questões e, em geral, tenderam a apontar seu próprio país como o mais competitivo. Porém alguns resultados foram interessantes, destacando o fato de que os empresários canadenses perceberam o Chile como país mais competitivo depois do próprio Canadá, com $15 \%$ das respostas, e apenas $2 \%$ deles lembraram-se de citar o Brasil (Figura 6), explicando, em parte, a pequena preocupação do Canadá com a concorrência brasileira.

Embora a maioria dos entrevistados tenha apontado seu próprio país como o melhor ambiente de negócios, o percentual do empresariado brasileiro que seguiu essa direção, com $48 \%$ das opiniões, foi mais que o dobro do percentual canadense, de 18\% (Figura 6). Esses resultados sugerem menor conhecimento do empresário brasileiro sobre o ambiente de negócios de madeira serrada em outros 
países, corroborando os resultados referentes à menor orientação ao mercado externo pelo empresário brasileiro, obtido por meio de dados secundários.

A grande maioria dos empresários brasileiros apontou o Brasil como o melhor ambiente para investir no segmento de madeira serrada, seguido por Estados Unidos, China e Canadá, com $8 \%$ das opiniões registradas. Os países da América do Sul foram pouco lembrados pelo empresário brasileiro, destacando-se a Argentina, o Chile e o Uruguai, com apenas 3,5\% das opiniões cada. A Indonésia foi mencionada em $6 \%$ das respostas (Figura 6).

Os motivos que levaram os empresários brasileiros a destacar o Brasil como o melhor ambiente de negócios são, principalmente, as vantagens relacionadas ao acesso à madeira barata e sustentável e a percepção de um mercado doméstico em rápido crescimento (Figura 7).

Os preços médios da madeira em tora para serraria, no Brasil e no Canadá, no período de 2003 a 2007, diferenciaram-se conforme o valor de suas moedas. Ambos os preços médios, no período, alcançaram valores de 57, porém, para o Brasil, em reais ( $\mathrm{R} \$$ ), e para o Canadá, em dólares canadenses (C\$). Considerando que o valor médio do dólar canadense, entre 2003 e 2007, foi o dobro do real, guardando as devidas limitações dessa comparação, pode-se dizer que a madeira no Brasil é mais barata que a do Canadá (IBGE, 2010; BRITISH COLUMBIA/BC, 2010).

$\mathrm{O}$ menor preço da madeira no Brasil decorre, principalmente, da alta produtividade das florestas plantadas no país. Segundo a Associação Brasileira de Produtores de Florestas Plantadas/ABRAF (2010), a produtividade média das florestas plantadas no Brasil gira em torno de $30 \mathrm{~m}^{3} /$ hectare/ano, seis vezes superior aos $5 \mathrm{~m}^{3} /$ hectare/ano do Canadá. Portanto, nesse aspecto, a percepção do empresário brasileiro é justificável.

A percepção dos empresários brasileiros, no que tange à vantagem comparativa do Brasil decorrente do crescimento do mercado interno, pode ser facilmente verificada pelas evoluções do PIB. Entre 2004 e 2008, a economia brasileira cresceu a uma taxa média de 5\%, praticamente o dobro do crescimento canadense para o mesmo período (UN, 2010).

Os empresários brasileiros que apontaram a China e os países desenvolvidos, como Estados Unidos e Canadá, entre os melhores ambientes de negócios, levaram em consideração os fatores disponibilidade de infraestrutura sofisticada, forte compromisso do governo em apoiar o desenvolvimento da indústria, disponibilidade de suporte técnico, ausência de excessiva burocracia e mínima regulação nos negócios (Figura 7).

Em relação à infraestrutura, parece existir um consenso entre analistas de diferentes áreas sobre as deficiências brasileiras nesse aspecto, haja vista a constante utilização da expressão "custo Brasil". Conforme estudo da Associação Brasileira da Indústria de Máquinas e Equipamentos/ABIMAQ (2010), o chamado "custo Brasil", conjunto de fatores que comprometem a competitividade e a eficiência da indústria nacional, encarece o produto brasileiro 36,27\%, em média, em relação aos fabricados na Alemanha e nos Estados Unidos. Se a comparação for com os Tigres Asiáticos ou a China, esta desvantagem é da ordem de $100 \%$.

Em geral, a percepção dos empresários no Canadá é de que não só o Chile, que possui uma estrutura florestal similar e com produtividades próximas à do Brasil, mas também o próprio Canadá e os Estados Unidos possuem grandes vantagens competitivas em relação a questões de âmbito florestal, pois o principal motivo que levou o empresário canadense a destacar esses países como os melhores ambientes de negócios foi o acesso a fonte de madeira barata e sustentável (Figura 7).

Embora as florestas no Canadá possuam uma baixa produtividade, a madeira produzida possui maior qualidade, permitindo maior rendimento no seu desdobramento. Além disso, o Canadá possui metade do seu território coberto por florestas, totalizando 417,6 milhões de hectares, dos quais 235 milhões de hectares são considerados florestas comerciais, e desse montante, apenas $0,4 \%$ é colhido por ano, permitindo um prazo mais que suficiente para a regeneração natural de suas florestas (REVISTA DA MADEIRA/REMADE, 2002).

As outras duas questões apontadas pelos empresários canadenses para a escolha do Canadá, do Chile e dos Estados Unidos como os países mais competitivos foram o forte compromisso do governo em apoiar o desenvolvimento da indústria, a ausência de excessiva burocracia e a mínima regulação governamental dos negócios. Essas características refletem a forte influência do governo no provimento de uma estrutura adequada para o desenvolvimento das empresas de madeira serrada e a baixa influência direta na sua atuação (Figura 7). 

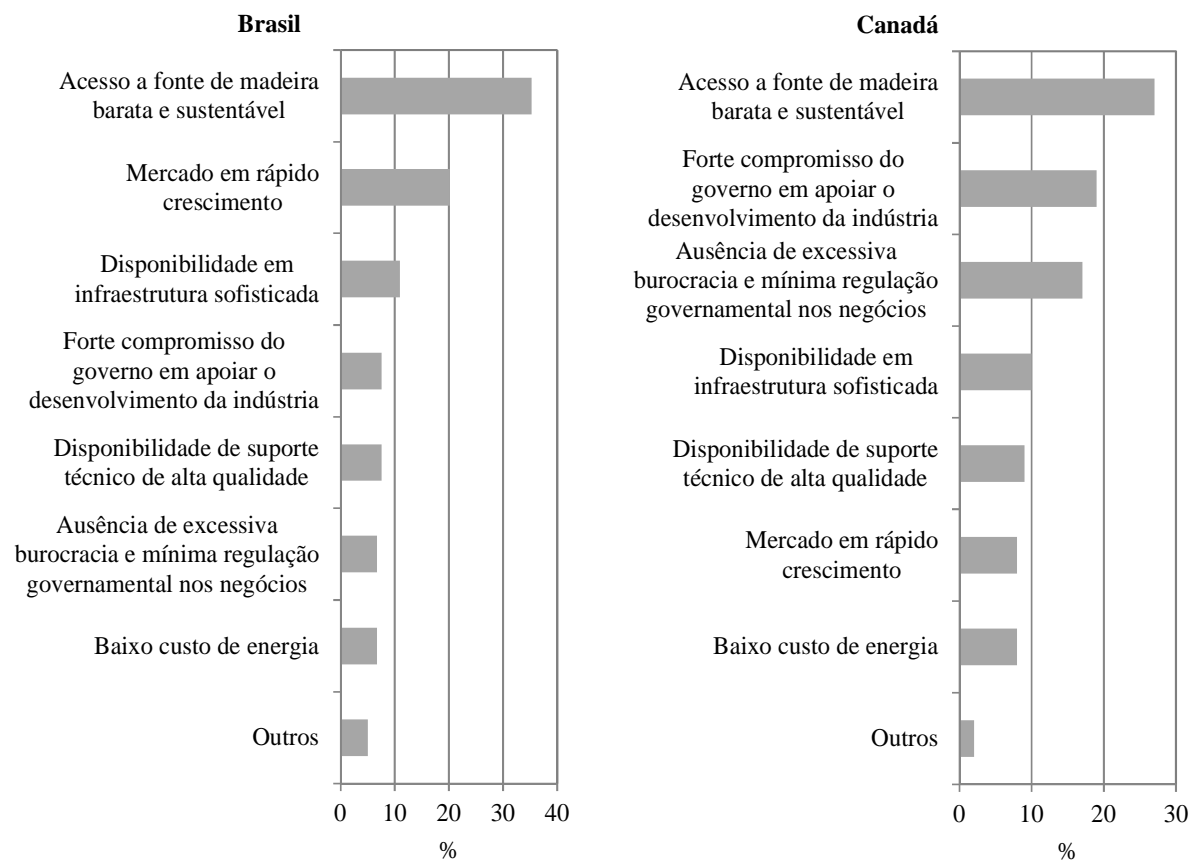

Figura 7. Principais razões para a escolha dos países que oferecem o melhor ambiente de negócios para investir no segmento de madeira serrada.

Figure 7. Main reasons for the choice of countries which offer the best business environment to invest in the softwood lumber segment.

Conforme o Departamento de Comércio dos Estados Unidos/USDC (2009), em estudo que avaliou a influência governamental para produção de madeira serrada em diversos países, o segmento de madeira serrada canadense recebe um tratamento diferenciado por seu governo, bem superior ao recebido pelas empresas brasileiras, em questões prioritariamente ligadas ao desenvolvimento tecnológico e à infraestrutura específica ao segmento de serrados.

Segundo o USDC (2009), os únicos subsídios governamentais no Brasil que ajudariam o segmento de madeira serrada, mesmo que indiretamente, são as linhas de crédito com juro subsidiado PROPFLORA e PRONAF Florestal -, que contribuiriam para produção de madeira a um preço inferior ao de livre mercado.

Para o Canadá, a USDC (2009) apontou várias medidas que são consideradas como subsídios pelo órgão, e como exemplos, têm-se:

- Oferta de madeira serrada inferior à adequada remuneração, levando a um dumping no preço da madeira em tora. Deve ser lembrado que, no Canadá, praticamente toda a oferta de madeira é proveniente de áreas governamentais, demonstrando mais uma vez o fato de que a baixa produtividade não é um problema para a sustentabilidade das florestas canadenses.

- Programa de diversificação econômica, introduzido em 1987, que apoia projetos comerciais e não comerciais para promoção do crescimento, do desenvolvimento e da diversificação nas províncias de Alberta, British Columbia, Manitoba e Saskatchewan.

- Programa de recursos naturais do Canadá (NRCAN). Em 2002, o governo canadense aprovou um total de C\$ 75 milhões em subsídios, visando o aumento da pesquisa e do desenvolvimento para a inovação de produtos de madeira.

- Programa de investimento para inovação florestal (FIIP), que entrou em vigor em $1^{\circ}$ de abril de 2002 , exclusivo na província British Columbia. Esse programa disponibilizou fundos para apoiar as atividades das universidades de pesquisa e ensino e de organizações e associações da indústria que produzem uma vasta gama de produtos de madeira. 
- Programa de imposto para florestas privadas na província de British Columbia, em que é cobrado um imposto inferior para propriedades florestais manejadas e voltadas à produção, quando comparadas às propriedades não manejadas, o que incentiva a extração da madeira.

- Programa de desenvolvimento de florestas privadas em Quebec, que dá incentivos aos proprietários de terra para plantar mais árvores, consequentemente aumentando a oferta de madeira disponível para produtores de madeira serrada. Além disso, alguns dos operadores de serrarias também possuem terrenos privados e se beneficiam diretamente desse programa.

- Programa de garantia de crédito ao setor florestal em Ontário. Esse programa foi anunciado em 2005 e tornou disponíveis $\mathrm{C} \$ 350$ milhões em empréstimos para estimular e impulsionar o investimento no setor florestal. As garantias de empréstimo podem ser para um período de dois a cinco anos e, geralmente, variam de C\$ 500 mil a um máximo de C $\$ 25$ milhões por beneficiado.

- Programa de manutenção e construção de estradas que possibilitem acesso às florestas de Ontário. Esse programa foi anunciado em 2006 e disponibiliza $\mathrm{C} \$ 75$ milhões para reembolsar às empresas florestais os custos da construção e manutenção primária de estradas para acesso secundário às florestas.

- Programa de apoio à indústria florestal, anunciado em 2006, para tornar disponíveis C\$ 425 milhões em financiamento para promover projetos de investimento e de modernização, com vistas a melhorar a produtividade e a competitividade da indústria de produtos florestais de Quebec.

- Crédito fiscal de $15 \%$, em Quebec, para as indústrias de produtos florestais, no que tange aos investimentos em equipamentos de fabricação e ao processamento de madeira até 2009.

- Medidas de gestão da floresta. Programa anunciado em 2006 pelo governo de Quebec, que disponibilizou C \$ 210 milhões para reduzir o custo das operações em silvicultura e C \$ 100 milhões em crédito de imposto reembolsável de $40 \%$ para a construção de estradas e pontes de acesso à floresta.

- Programa de promoção à madeira. O governo de Ontário oferece C\$1 milhão por ano de financiamento para as indústrias de produtos florestais, como incentivo à produção de bens de maior valor agregado.

- Programa de bônus no norte de Ontário. O governo de Ontário disponibiliza cerca de C\$ 13 milhões em bônus para as novas empresas e para aquelas em crescimento, beneficiando também as serrarias da região.

- Iniciativa à competitividade de longo prazo para a indústria florestal canadense. Programa que prevê o financiamento público para a pesquisa e o desenvolvimento direcionado à indústria de base florestal.

Provavelmente, além do PRONAF florestal e do PROPFLORA, outras medidas governamentais contribuam para o desenvolvimento do setor florestal brasileiro, não esquecendo o forte apoio que ele obteve no passado, por meio da Lei dos Incentivos Fiscais, em vigor entre 1966 e 1986, bem como os apoios para o segmento de papel e celulose, via primeiro e segundo programa nacional de papel e celulose, na década de 80 , apoios esses que indiretamente ajudaram o segmento de madeira sólida, porém é nítido o maior suporte recebido pelos empresários canadenses.

\section{CONCLUSÕES}

- A principal diferença entre o Brasil e o Canadá na produção de madeira serrada deve-se muito mais ao grau de desenvolvimento do que ao tamanho dos seus segmentos de serrados.

- Além de o Canadá apresentar vantagens naturais por ser um país desenvolvido, as suas empresas de madeira serrada apresentaram vantagens competitivas provenientes do maior porte, especialização e orientação ao mercado externo.

- Ao contrário do governo brasileiro, frequentemente acusado de não propiciar as condições adequadas de produção, o governo do Canadá mostrou-se mais atencioso com o desenvolvimento da indústria da madeira canadense.

- O empresário canadense apresentou um maior conhecimento sobre comércio internacional e uma percepção sobre a competitividade direcionada ao lucro, indicando uma preocupação alinhada com a qualidade e evolução tecnológica, questões fundamentais para a competitividade no mundo moderno. 


\section{REFERÊNCIAS}

ALMEIDA, A. N. Estudo econométrico da demanda e oferta de madeira em tora para o processamento mecânico no Estado do Paraná. 217 f. Dissertação (Mestrado em Ciências Florestais) Universidade Federal do Paraná, Curitiba, 2006.

ASSOCIAÇÃO BRASILEIRA DA INDÚSTRIA DE MÁQUINAS E EQUIPAMENTOS (ABIMAQ). Uma avaliação do "Custo Brasil" e seu impacto na competitividade da indústria brasileira. Disponível em: <http://www.fiesp.com.br/irs/cosec/pdf/transparencias_reuniao_cosec_08_03_10__mario_bernardini_-_custo_brasil___apresentacao_final.pdf>. Acesso em: 07/11/2010.

ASSOCIAÇÃO BRASILEIRA DA INDÚSTRIA DE MADEIRA PROCESSADA MECANICAMENTE (ABIMCI). Estudo Setorial, 2008. Disponível em: <http://www.abimci.com.br/dmdocuments/ ABIMCI_Estudo_Setorial_2008.pdf>. Acesso em: 07/11/2010.

ASSOCIAÇÃO BRASILEIRA DE PRODUTORES DE FLORESTAS PLANTADAS (ABRAF). Anuário Estatístico, 2005, 2006, 2007 e 2008. Disponível em: <http://www.abraflor.org.br/estatisticas .asp>. Acesso em: 07/11/2010.

AXINN, C. N. Export performance: do managerial perceptions make a difference? International marketing Review, v. 5, n. 5, p. 67 - 71, 1988.

AWH, R. Y. Microeconomia: teoria e aplicações. Rio de Janeiro: Livros Técnicos e Científicos, 1979. 460 p.

BRITISH COLUMBIA (BC). Log market reports. Disponível em: <http://www.for.gov.bc.ca/ hva/logreports_coast.htm?earlier>. Acesso em: 07/11/2010.

DIAMONTOPOULUS, A.; INGLIS, K. Identifying differences between high-and low involvement exporters. International Marketing Review, v. 5, n. 2, p. 52 - 60, 1988.

DICHTL, E.; KOGLMAYR, H. G.; MULLER, S. International orientation as a precondition for export success. Journal of International Business Studies, p. 1940, 1993.

FREEMAN, C. Critical survey: the economics of technical change. Cambridge Journal of Economics, v. 18, p. $463-514,1994$.

GAPMINDER. Disponível em: <http://www.gapminder.org/>. Acesso em: 07/11/2010.

GHOSHAL, S.; TANURE, B. Estratégia e gestão empresarial: construindo empresas brasileiras de sucesso. Rio de Janeiro: Elsevier, 2004. 271 p.

GUAN, J. C.; YAM, R. C. M.; MOK, C. K.; MA, N. A study of the relationship between competitiveness and technological innovation capability based on DEA models. European Journal of Operational Research, v. 170, p. 971 - 986, 2006.

INSTITUTO BRASILEIRO DE GEOGRAFIA E ESTATÍSTICA (IBGE). Anuário estatístico brasileiro. Disponível em: <http://www.ibge.gov.br/home/>. Acesso em: 07/11/2010.

LEVINE, D. M.; BERENSON, M. L.; STEPHAN, D. Estatística: teoria e aplicações usando Microsoft Excel em português. Rio de Janeiro: LTC, 2000.

MARTINS, G. A. Estatística geral e aplicada. 3. ed. São Paulo: Atlas, 2006. 421 p.

NAÇÕES UNIDAS (UN). Banco de dados das Nações Unidas. Disponível em: <http://data.un.org/Search.aspx?q=GDP>. Acesso em: 07/11/2010.

NATURAL RESOURCES CANADA (NRC). Disponível em: <http://canadaforests.nrcan.gc.ca/ statsprofile/economicimpact/ca>. Acesso em: 07/11/2010.

ORGANIZAÇÃO DAS NAÇÕES UNIDAS PARA AGRICULTURA E ALIMENTAÇÃO (FAO). Estatísticas florestais. Disponível em: <http://faostat.fao.org/site/291/default.aspx>. Acesso em: $07 / 11 / 2010$. 
PORTER, M. E. A vantagem competitiva das nações. Rio de Janeiro: Campus, 1993.

POSSAS, M. L. Competitividade: fatores sistêmicos e política industrial - implicações para o Brasil. In: CASTRO, A. B. de; POSSAS, M. L.; PROENÇA, A. (orgs.). Estratégias empresariais da indústria brasileira: discutindo mudanças. Rio de Janeiro: Forense Universitária, 1996. p. 75 - 117.

PROGRAMA DAS NAÇÕES UNIDAS PARA O DESENVOLVIMENTO (PNUD). Disponível em: <http://hdr.undp.org/en/>. Acesso em: 07/11/2010.

REVISTA DA MADEIRA (REMADE). Florestas canadenses: um vasto e complexo recurso. ed. n. 66, ago./2002.

SEM, F. K.; EGELHOFF, W. G. Innovative capabilities of a firm and the use of technical alliances. IEEE Transactions on Engineering Management, v. 47, p. 174 - 183, 2000.

SPELTER, H.; ALDERMAN, M. Profile 2005: softwood sawmills in the United States and Canada. Madison, WI: U.S. Department of Agriculture, Forest Service, 2005. 15 p. (Research Paper FPL-RP-630).

UNITED STATE DEPARTMENT OF COMMERCE (USDC). Softwood lumber subsidies report to the congress. Dec./2009. Disponível em: <http://ia.ita.doc.gov/sla2008/reports /softwood-lumbersubsidies-report-121809.pdf >. Acesso em: 07/11/2010.

WEYNE, G. R. de S. Determinação do tamanho da amostra em pesquisas experimentais na área de saúde. Arq. Med. AVC, v. 29, n. 2, jul./dez. 2004. 
